\title{
Age, Pulse, Urea and Albumin (APUA) Model: A Tool for Predicting in-Hospital Mortality of Community-Acquired Pneumonia Adapted for Patients with Type 2 Diabetes
}

This article was published in the following Dove Press journal: Diabetes, Metabolic Syndrome and Obesity: Targets and Therapy

\section{Chun-Ming $\mathrm{Ma}^{\prime}$ \\ Ning Wang ${ }^{2}$ \\ Quan-Wei Su ${ }^{3}$ \\ Ying Yan $^{3}$ \\ Fu-Zai Yin (D)'}

'Department of Endocrinology, The First Hospital of Qinhuangdao, Qinhuangdao, Hebei, People's Republic of China; ${ }^{2}$ Department of Internal Medicine, Hebei Medical University, Shijiazhuang, Hebei, People's Republic of China; ${ }^{3}$ Department of Internal Medicine, Chengde Medical College, Chengde, Hebei, People's Republic of China
Correspondence: Fu-Zai Yin Email yinfuzai62@163.com
Objective: The aim of this study was to develop a tool for predicting in-hospital mortality of community-acquired pneumonia (CAP) in patients with type 2 diabetes (T2DM).

Methods: A retrospective study was conducted on 531 CAP patients with T2DM at The First Hospital of Qinhuangdao. The primary outcome was in-hospital mortality. Variables to develop the nomogram were selected using multiple logistic regression analysis. Discrimination was evaluated using receiver operating characteristic (ROC) curve. Calibration was evaluated using the Hosmer-Lemeshow test and calibration plot.

Results: Multiple logistic regression analysis showed that age, pulse, urea and albumin (APUA) were independent risk predictors. Based on these results, we developed a nomogram (APUA model) for predicting in-hospital mortality of CAP in T2DM patients. In the training set, the area under the curve (AUC) of the APUA model was 0.814 (95\% CI: 0.770-0.853), which was higher than the AUCs of albumin alone, CURB-65 and Pneumonia Severity Index (PSI) class $(p<0.05$ ). The Hosmer-Lemeshow test $\left(\chi^{2}=5.298, p=0.808\right)$ and calibration plot $(p=0.802)$ showed excellent agreement between the predicted possibility and the actual observation in the APUA model. The results of the validation set were similar to those of the training set.

Conclusion: The APUA model is a simple and accurate tool for predicting in-hospital mortality of CAP, adapted for patients with T2DM. The predictive performance of the APUA model was better than CURB-65 and PSI class.

Keywords: community-acquired pneumonia, albumin, mortality, type 2 diabetes

\section{Plain Language Summary}

\section{Current Knowledge}

Community-acquired pneumonia (CAP) is more common in patients with diabetes, especially type 2 diabetes (T2DM). CURB-65 and pneumonia severity index (PSI) are two classical tools for evaluating the severity of CAP. However, the predictive performances of CURB-65 and PSI class were poor in patients with diabetes. Albumin is a protein made by the liver that plays many important roles. Low serum albumin was associated with the risk of mortality in T2DM patients with infection.

\section{What This Paper Contributes to the Existing Knowledge}

In this study, age, pulse, urea and albumin (APUA) model were independent risk predictors for in-hospital mortality of CAP in T2DM patients. Based on these 
results, we developed a nomogram (APUA model) for predicting in-hospital mortality of CAP in T2DM patients. The APUA model is a simple and accurate tool for predicting in-hospital mortality of CAP, adapted for patients with T2DM. The predictive performance of the APUA model was better than CURB-65 and PSI class.

\section{Introduction}

Community-acquired pneumonia (CAP) is a common respiratory disease, with an incidence of 1.76-9.6 per 1000 person-years. ${ }^{1-5}$ Diabetes is another global problem. About 463 million adults were living with diabetes worldwide in $2019 .^{6}$ Patients with diabetes have an increased risk of up to 1.4 for CAP. ${ }^{7}$ Type 2 diabetes (T2DM) is the most common type. Therefore, CAP is more common in patients with diabetes, especially T2DM.

The outcomes varied enormously between different CAP patients, from rapid recovery to death. CURB-65 and Pneumonia Severity Index (PSI) are two classical tools for evaluating the severity of CAP and are recommended by several CAP guidelines. ${ }^{8-11}$ A previous metaanalysis showed that the area under the curves (AUCs) of CURB-65 and PSI were about 0.8 for predicting 30-day mortality in hospitalized CAP patients. ${ }^{12}$ However, the predictive performances of CURB-65 and PSI class were poor in patients with diabetes. The AUCs of CURB-65 and PSI were only 0.669 and 0.682 in patients with T2DM. ${ }^{13}$

Albumin is a protein made by the liver that plays many important roles. Numerous studies confirmed that serum albumin correlated with short-term and long-term mortality of CAP. $^{14-17}$ In the CAP-China network, albumin level was also an independent predictor of 60-day mortality of CAP. $^{18}$

Serum albumin is closely related to the risk of death in T2DM. The level of albumin was negatively correlated with early mortality among elderly patients with T2DM. ${ }^{19}$ Low albumin levels increase the risk of mortality in diabetic patients with diabetic foot and chronic kidney disease. ${ }^{20,21}$ Low serum albumin was also associated with the risk of mortality in T2DM patients with infection. In T2DM, low albumin levels increase the risk of mortality in patients with community-onset bacterial bloodstream infections. $^{22,23}$

Therefore, in this study, we developed a tool for predicting in-hospital mortality of CAP in patients with T2DM.

\section{Methods}

\section{Subjects}

The patients in this study were included from a survey on in-hospital mortality of CAP in patients with T2DM at our hospital. All subjects were adult inpatients, who were hospitalized due to CAP between January 2015 and December 2018. Patients with type 1 diabetes, other specific types of diabetes, no clear type classification, pre-diabetes, pregnancy and obstetric infection were excluded. Patients with missing clinical data on serum albumin, CURB-65 and PSI were also excluded. Eventually, 2365 patients, aged $66.6 \pm 17.3$ years, were enrolled. Among these patients, 531 were T2DM patients $(22.5 \%)$, while 1834 were non-diabetics. This study was approved by the ethics committee of the First Hospital of Qinhuangdao.

\section{Data Collection}

Initial data after admission were extracted from the Hospital Information System. Sociodemographic variables included age, gender and ethnicity. Serum albumin, CURB-65 and PSI were also collected. The scores of CURB-65 and PSI were calculated. ${ }^{24,25}$ According to the PSI score, the patients were classified into five risk classes. The primary outcome was in-hospital mortality.

\section{Statistical Analyses}

The statistical analyses were performed using SPSS 24.0 (SPSS Inc, Chicago, IL), R version 3.6.1 (R Development Core Team; http://www.r-project.org) and MedCalc15.2.2 (Ostend, Belgium) software. A $p$-value $<0.05$ was considered statistically significant.

For nomogram development and validation, we randomly assigned $70 \%$ of the participants to the training set and $30 \%$ to the validation set. The characteristics of the two sets were described and compared using chisquare test or Student's $t$-test. Variables to develop the nomogram were selected using multiple logistic regression analysis.

Nomogram validation consisted of two parts, discrimination and calibration. Discrimination was evaluated using receiver operating characteristic (ROC) curve, net reclassification improvement (NRI) and integrated discrimination improvement (IDI). Calibration was evaluated using the Hosmer-Lemeshow test and calibration plot. Clinical 
Table I Characteristics of the Training and Validation Set in Community-Acquired Pneumonia Patients with Type 2 Diabetes

\begin{tabular}{|c|c|c|c|c|c|c|}
\hline Variables & & $\begin{array}{l}\text { All } \\
(N=53 I)\end{array}$ & $\begin{array}{l}\text { Training Set } \\
(\mathrm{N}=359)\end{array}$ & $\begin{array}{l}\text { Validation Set } \\
(\mathrm{N}=\mid 72)\end{array}$ & $\operatorname{tor} \chi^{2}$ & $\boldsymbol{P}$ \\
\hline Sex (males/females) & & $305 / 226$ & $212 / 147$ & $93 / 79$ & 1.181 & 0.277 \\
\hline Age (years) & & $71.7 \pm 11.7$ & $72.0 \pm 11.6$ & $71.1 \pm 11.9$ & 0.826 & 0.409 \\
\hline \multirow[t]{3}{*}{ Ethnicity [n(\%)] } & Han & $509(95.9)$ & $342(95.3)$ & $167(97.1)$ & 2.879 & 0.237 \\
\hline & Other & $15(2.8)$ & $13(3.6)$ & $2(1.2)$ & & \\
\hline & Unknown & $7(1.3)$ & $4(I .1)$ & $3(1.7)$ & & \\
\hline Confusion [n(\%)] & & 63(II.9) & $43(12.0)$ & $20(I 1.6)$ & 0.014 & 0.907 \\
\hline Temperature $\left({ }^{\circ} \mathrm{C}\right)$ & & $36.9 \pm 0.8$ & $36.9 \pm 0.8$ & $36.9 \pm 0.8$ & 0.390 & 0.697 \\
\hline Respiratory rate (/min) & & $21.1 \pm 3.7$ & $21.2 \pm 3.8$ & $20.8 \pm 3.4$ & 0.899 & 0.369 \\
\hline Pulse (/min) & & $89.7 \pm 18.2$ & $90.7 \pm 18.5$ & $87.6 \pm 17.4$ & 1.851 & 0.065 \\
\hline SBP $(\mathrm{mmHg})$ & & $135.8 \pm 24.7$ & $134.9 \pm 24.3$ & $137.6 \pm 25.5$ & 1.168 & 0.243 \\
\hline $\mathrm{DBP}(\mathrm{mmHg})$ & & $77.5 \pm 13.8$ & $77.0 \pm 12.7$ & $78.4 \pm 15.9$ & 1.103 & 0.271 \\
\hline Urea (mmol/L) & & $8.19 \pm 5.85$ & $8.20 \pm 5.79$ & $8.16 \pm 5.98$ & 0.075 & 0.940 \\
\hline Sodium (mmol/L) & & $137.1 \pm 6.6$ & $|37| \pm 6.7$. & $|37| \pm 6.3$. & 0.081 & 0.935 \\
\hline Glucose (mmol/L) & & $10.8 \pm 5.0$ & $10.9 \pm 5.2$ & $10.5 \pm 4.5$ & 0.815 & 0.415 \\
\hline Hematocrit (\%) & & $35.9 \pm 6.7$ & $36.1 \pm 6.7$ & $35.5 \pm 6.7$ & 1.002 & 0.317 \\
\hline Albumin $(g / L)$ & & $34.2 \pm 5.2$ & $34.5 \pm 5.1$ & $33.7 \pm 5.5$ & 1.683 & 0.093 \\
\hline CURB-65 Score & & $1.42 \pm 0.99$ & $1.44 \pm 0.98$ & $1.37 \pm 1.01$ & 0.744 & 0.457 \\
\hline PSI Score & & $96.5 \pm 29.5$ & $96.9 \pm 29.5$ & $95.5 \pm 29.6$ & 0.524 & 0.600 \\
\hline Death [n(\%)] & & $47(8.9)$ & $34(9.5)$ & $13(7.6)$ & 0.527 & 0.468 \\
\hline
\end{tabular}

Abbreviations: SBP, systolic blood pressure; DBP, diastolic blood pressure; PSI, Pneumonia Severity Index.

effectiveness was evaluated using the decision curve analysis (DCA).

\section{Results}

This study enrolled 531 CAP patients with T2DM (305 males and 226 females), aged $71.7 \pm 11.7$ years. The participants were randomly divided into the training set $(n=359)$ and the validation set $(n=172)$. No statistically significant differences in baseline characteristics, CURB-65, PSI and in-hospital mortality were observed between the two sets (Table 1).

In the univariate analyses, the frequencies of age $\geq 85$ yrs, respiratory rate $\geq 30 / \mathrm{min}$, pulse $\geq 125 / \mathrm{min}$, urea $\geq 11$ $\mathrm{mmol} / \mathrm{L}$, albumin $25-34.9 \mathrm{~g} / \mathrm{L}$ and albumin $\geq 35 \mathrm{~g} / \mathrm{L}$ were significantly higher in the dead patients than in the surviving patients $(p<0.05)$ (Table 2). Multivariate analyses were performed using the significant risk factors determined in the univariate analysis. Multiple logistic regression analysis showed that age, pulse, urea and albumin (APUA) were independent risk predictors (Table 3).

Based on these results, we developed a nomogram (APUA model) for predicting in-hospital mortality of CAP in T2DM patients. The nomogram illustrated that serum albumin had the largest contribution to prognosis in the APUA model (Figure 1). For example, a patient aged 87 years (62.02 points) had pulse $94 / \mathrm{min}$ ( 0 point), urea $7.3 \mathrm{mmol} / \mathrm{L}(0$ point) and albumin $30.6 \mathrm{~g} / \mathrm{L}(63.23$ points). The total score was $62.02+0+0+63.23=$ 125.25, and the predicted risk of in-hospital mortality was $17.6 \%$. A web calculator based on the APUA model was developed to estimate the individualized risk of inhospital mortality (https://doctorma.shinyapps.io/ DynNomapp/).

In the training set, the AUC of the APUA model was 0.814 (95\% CI: $0.770-0.853)$, which was higher than the AUCs of albumin alone, CURB-65 and PSI class $(p<0.05)$ (Table 4) (Figure 2A). Compared with albumin alone, CURB-65 and PSI class, the NRIs of the APUA model were $0.861(0.533-1.189), 0.766(0.462-1.070)$ and 0.815 (0.493-1.137), respectively ( $p<0.001)$ (Table 5). The IDIs of the APUA model were $0.080 \quad(0.032-0.127), 0.087$ $(0.040-0.134)$ and $0.076(0.023-0.128)$, respectively $(p<0.05)$ (Table 5). The Hosmer-Lemeshow test $\chi^{2}=5.298$, $p=0.808)$ and calibration plot $(p=0.802)$ showed excellent agreement between the predicted possibility and the actual observation in the APUA model (Figure 3A). In the DCA, the APUA model showed better net benefit than albumin alone, CURB-65 and PSI class (Figure 4A). 
Table 2 Characteristics of the Survival and Death Patients in the Training Set

\begin{tabular}{|c|c|c|c|c|}
\hline Variables & $\begin{array}{l}\text { Survival } \\
(\mathrm{N}=325)\end{array}$ & $\begin{array}{l}\text { Death } \\
(N=34)\end{array}$ & $\operatorname{tor} \chi^{2}$ & $P$ \\
\hline $\begin{array}{l}\text { Sex (males/females) } \\
\text { Age (years) } \\
\text { Age<64yrs } \\
\text { Age } 65 \sim 84 y r s \\
\text { Age } \geq 85 y \text { ys }\end{array}$ & $\begin{array}{l}193 / 132 \\
71.5 \pm 11.5 \\
89(27.4) \\
196(60.3) \\
40(12.3)\end{array}$ & $\begin{array}{l}19 / 15 \\
76.7 \pm 10.9 \\
4(11.8) \\
21(61.8) \\
9(26.5)\end{array}$ & $\begin{array}{l}0.156 \\
2.497 \\
7.433\end{array}$ & $\begin{array}{l}0.693 \\
0.013 \\
0.024\end{array}$ \\
\hline $\begin{array}{l}\text { Ethnicity [n(\%)] } \\
\text { Han } \\
\text { Other } \\
\text { Unknown }\end{array}$ & $\begin{array}{l}310(95.4) \\
11(3.4) \\
4(1.2)\end{array}$ & $\begin{array}{l}32(94.1) \\
2(5.9) \\
0(0.0)\end{array}$ & 0.954 & 0.621 \\
\hline $\begin{array}{l}\text { Confusion }[\mathrm{n}(\%)] \\
\text { Temperature }\left({ }^{\circ} \mathrm{C}\right) \\
\text { Temperature }<35^{\circ} \mathrm{C} \text { or } \geq 40^{\circ} \mathrm{C}[\mathrm{n}(\%)] \\
\text { Respiratory rate }(/ \mathrm{min}) \\
\text { Respiratory rate } \geq 30 / \mathrm{min}[\mathrm{n}(\%)] \\
\text { Pulse }(/ \mathrm{min}) \\
\text { Pulse } \geq 125 / \mathrm{min}[\mathrm{n}(\%)] \\
\text { SBP }(\mathrm{mmHg}) \\
\text { DBP }(\mathrm{mmHg}) \\
\text { SBP }<90 \mathrm{mmHg}[\mathrm{n}(\%)] \\
\text { Low } \mathrm{BP}(\mathrm{SBP}<90 \text { or DBP} \leq 60 \mathrm{mmHg})[\mathrm{n}(\%)] \\
\text { Urea }(\mathrm{mmol} / \mathrm{L}) \\
\text { Urea } \geq \mathrm{I} / \mathrm{mmol} / \mathrm{L}[\mathrm{n}(\%)] \\
\text { Sodium }(\mathrm{mmol} / \mathrm{L}) \\
\text { Sodium }<130 \mathrm{mmol} / \mathrm{L}[\mathrm{n}(\%)] \\
\text { Glucose }(\mathrm{mmol} / \mathrm{L}) \\
\text { Glucose } \geq 14 \mathrm{mmol} / \mathrm{L}[\mathrm{n}(\%)] \\
\text { Hematocrit }(\%) \\
\text { Hematocrit }<30 \%[\mathrm{n}(\%)] \\
\text { Albumin }(\mathrm{g} / \mathrm{L}) \\
\text { Albumin }<25 \mathrm{~g} / \mathrm{L} \\
\text { Albumin } 25 \sim 34.9 \mathrm{~g} / \mathrm{L} \\
\text { Albumin } \geq 35 \mathrm{~g} / \mathrm{L}\end{array}$ & $\begin{array}{l}36(\mid 1.1) \\
36.9 \pm 0.8 \\
0(0.0) \\
21.0 \pm 3.6 \\
14(4.3) \\
89.2 \pm 17.1 \\
12(3.7) \\
135.2 \pm 23.6 \\
77.0 \pm \mid 2.6 \\
6(1.8) \\
35(10.8) \\
7.87 \pm 5.5 \mid \\
53(16.3) \\
137.4 \pm 6.6 \\
31(9.5) \\
10.78 \pm 5.06 \\
61(18.8) \\
36.4 \pm 6.8 \\
56(17.2) \\
34.8 \pm 5.0 \\
165(50.8) \\
155(47.7) \\
5(1.5)\end{array}$ & $\begin{array}{l}7(20.6) \\
36.9 \pm 1.0 \\
0(0.0) \\
22.7 \pm 5.7 \\
5(14.7) \\
105.4 \pm 24.8 \\
6(17.6) \\
132.1 \pm 30.0 \\
76.6 \pm 13.4 \\
2(5.9) \\
4(11.8) \\
11.32 \pm 7.37 \\
16(47.1) \\
134.4 \pm 7.9 \\
6(17.6) \\
12.14 \pm 6.66 \\
8(23.5) \\
34.0 \pm 5.9 \\
6(17.6) \\
31.7 \pm 4.7 \\
5(14.7) \\
26(76.5) \\
3(8.8)\end{array}$ & $\begin{array}{l}1.816 \\
0.312 \\
1.667 \\
4.727 \\
3.711 \\
9.826 \\
0.579 \\
0.193 \\
\\
0.000 \\
3.350 \\
18.747 \\
2.508 \\
1.400 \\
1.443 \\
0.449 \\
1.945 \\
0.004 \\
3.465 \\
20.840\end{array}$ & $\begin{array}{l}0.178 \\
0.755 \\
0.104 \\
0.030 \\
0.001 \\
0.002 \\
0.566 \\
0.847 \\
0.170^{*} \\
1.000 \\
0.001 \\
<0.001 \\
0.013 \\
0.237 \\
0.150 \\
0.503 \\
0.053 \\
0.951 \\
0.001 \\
<0.001\end{array}$ \\
\hline
\end{tabular}

Note: *Fisher's exact test.

Abbreviations: SBP, systolic blood pressure; DBP, diastolic blood pressure.

In the validation set, the AUC of the APUA model was 0.796 (0.728-0.854), which was higher than the AUCs of albumin alone, CURB-65 and PSI class, although without statistically significant differences $(p>0.05)$ (Table 4) (Figure 2B). Compared with albumin alone, CURB-65 and PSI class, the NRIs of the APUA model were 0.599 (0.041-1.157), $0.693(0.170-1.216)$ and 0.643 (0.1191.166), respectively $(p<0.05)$ (Table 5). Compared with albumin alone, CURB-65 and PSI class, the IDIs of the APUA model were $0.109(0.027-0.191)$ and 0.086 $(0.005-0.168)$, respectively $(p<0.05) \quad$ (Table 5$)$. The Hosmer-Lemeshow test $\left(\chi^{2}=7.426, \quad p=0.593\right)$ and calibration plot $(p=0.181)$ showed excellent agreement between the predicted possibility and the actual observation in the APUA model (Figure 3B). In the DCA, the APUA model showed better net benefit than albumin alone, CURB-65 and PSI class (Figure 4B).

The sensitivities, specificities and Youden's index are shown in Table 6. The optimal cutoff point of the APUA model was the predicted risk of in-hospital mortality $\geq 10 \%$. The sensitivity was $68.1 \%$ and the specificity was $80.2 \%$. The patients were divided into five groups according to the predicted risk of mortality by the APUA model. The actual mortalities increased 
Table 3 The Risk Factors of in-Hospital Mortality in the Training Set

\begin{tabular}{|c|c|c|c|c|}
\hline Variables & & OR & $95 \% \mathrm{Cl}$ & $\mathbf{P}$ \\
\hline \multirow[t]{3}{*}{ Aging } & Age $<64 y r s$ & I & & \\
\hline & Age $65 \sim 84 y r s$ & 2.224 & $0.691 \sim 7.159$ & 0.180 \\
\hline & Age $\geq 85 \mathrm{yrs}$ & 4.780 & |.299 17.59| & 0.019 \\
\hline Pulse $\geq 125 / \mathrm{min}$ & & 3.782 & $1.139 \sim 12.558$ & 0.030 \\
\hline Urea $\geq \mathrm{I} / \mathrm{mmol} / \mathrm{L}$ & & 3.510 & I.583 7.784 & 0.002 \\
\hline \multirow[t]{3}{*}{ Hypoproteinemia } & Albumin $\geq 35 \mathrm{~g} / \mathrm{L}$ & I & & \\
\hline & Albumin $25 \sim 34.9$ & 4.929 & I.787 13.595 & 0.002 \\
\hline & Albumin $<25 \mathrm{~g} / \mathrm{L}$ & 12.463 & $1.933 \sim 80.353$ & 0.008 \\
\hline
\end{tabular}

Notes: Multiple logistic regression analysis, in-hospital mortality was considered as the dependent variables in a multiple logistic regression analysis with aging, respiratory rate $\geq 30 / \mathrm{min}$, pulse $\geq 125 / \mathrm{min}$, urea $\geq 1 / \mathrm{mmol} / \mathrm{L}$ and hypoproteinemia as independent variables.

Abbreviations: $\mathrm{OR}$, odds ratio; $\mathrm{Cl}$, confidence interval.

with the predicted risk of mortality by the APUA model (Table 7).

\section{Discussion}

This study established a tool termed the APUA model for predicting mortality of CAP, adapted for patients with T2DM. The APUA model is based on serum albumin, and consists of age, pulse, urea and albumin. This model has several advantages. First, the APUA model is relatively simpler and consists of only four risk factors. Urea and albumin can be tested in both primary and tertiary hospitals. Hence, the APUA model can be used in many medical institutions. Second, the APUA model is a fast assessment system. These factors can be rapidly obtained after admission, and the severity of CAP can be quickly evaluated by the APUA model. Moreover, a web calculator was developed, which is convenient for use in clinical application. Third, the APUA model is suitable for T2DM patients with CAP. In T2DM patients with CAP, simple APUA model was superior to CURB65 and PSI class. The AUCs of the APUA model were about 0.8 for predicting in-hospital mortality of CAP, and were higher than CURB-65 and PSI class. NRI and IDI are two novel metrics for evaluating improvement in discrimination. AUC, NRI and IDI offer complementary information. In this study, the results of NRI and IDI were in accordance with the results of AUC. DCA was performed to assess the performance of the APUA model. The net benefit of the APUA model was better than CURB-65 and PSI class.

Studies from Japan and Korea showed that serum albumin is not less accurate than CURB-65 or PSI class for predicting 30-day mortality in CAP patients. $^{26,27}$ In this study, hypoalbuminemia was closely correlated with in-hospital mortality of CAP in T2DM patients. Compared to T2DM patients with albumin $\geq 35$ $\mathrm{g} / \mathrm{L}$, T2DM patients with albumin 25-34.9 $\mathrm{g} / \mathrm{L}$ [OR= 4.929] and albumin $<25 \mathrm{~g} / \mathrm{L}[\mathrm{OR}=12.463]$ were more likely to die at the time of hospitalization. The predictive accuracy of albumin alone was similar to CURB-65 or PSI class, which may be related to the following mechanisms. First, hypoalbuminemia was common in

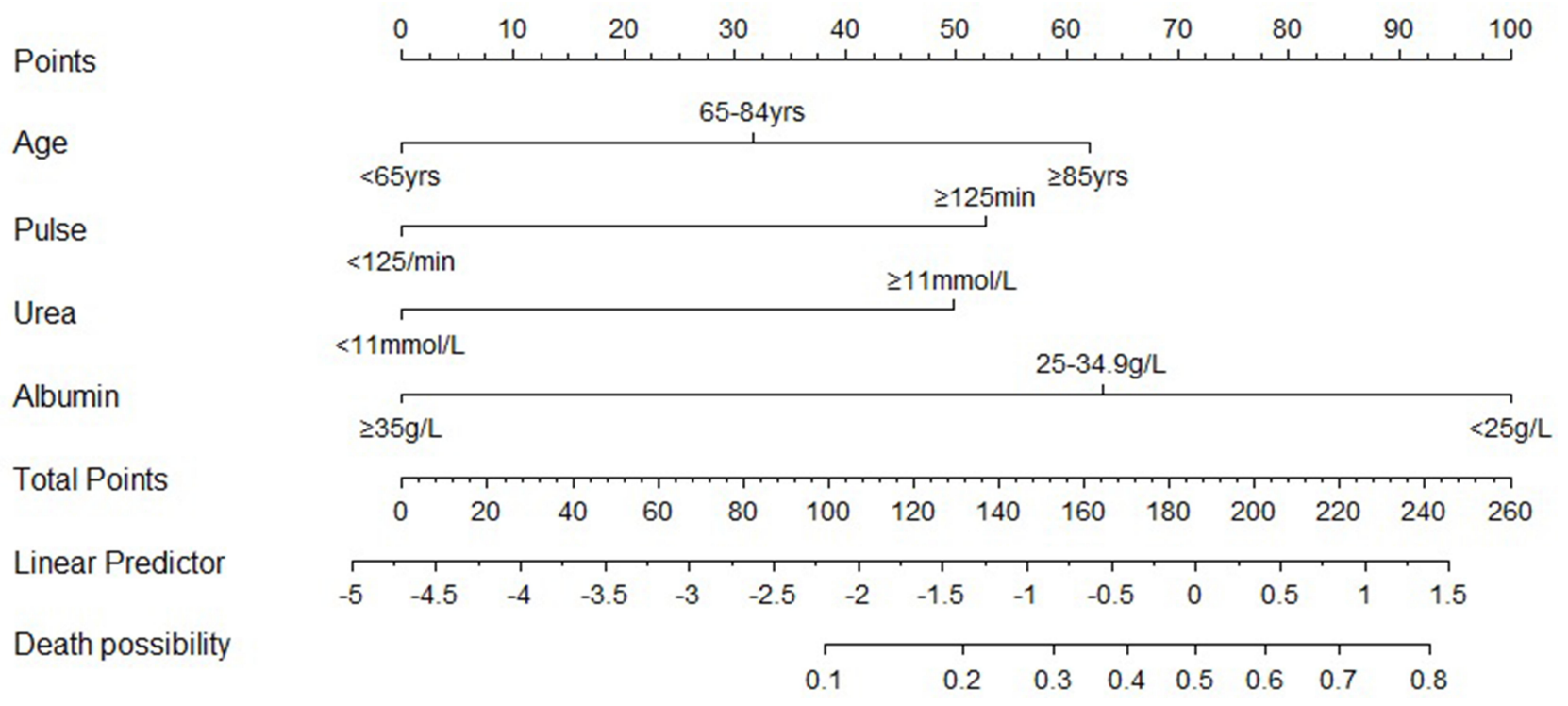

Figure I Nomogram for predicting the risk of in-hospital mortality in community-acquired pneumonia patients with type 2 diabetes. 
Table 4 The Accuracy of APUA Model, Serum Albumin Alone, CURB-65 and PSI Class for Evaluating the Risk of in-Hospital Mortality in Community-Acquired Pneumonia Patients with Type 2 Diabetes

\begin{tabular}{|c|c|c|c|c|c|}
\hline Variables & AUC (95\% Cl) & SE & $P$ & P* & $P^{\#}$ \\
\hline \multicolumn{6}{|c|}{ Training set $(\mathrm{N}=359)$} \\
\hline APUA model & $0.8 \mid 4(0.770 \sim 0.853)$ & 0.034 & $<0.001$ & & \\
\hline Albumin & $0.695(0.645 \sim 0.743)$ & 0.037 & $<0.001$ & $<0.001$ & \\
\hline CURB-65 & $0.686(0.635 \sim 0.733)$ & 0.045 & $<0.001$ & 0.002 & 0.864 \\
\hline PSI class & $0.710(0.66 \mid \sim 0.757)$ & 0.044 & $<0.001$ & 0.020 & 0.804 \\
\hline \multicolumn{6}{|c|}{ Validation set $(N=172)$} \\
\hline APUA model & $0.796(0.728 \sim 0.854)$ & 0.076 & $<0.001$ & & \\
\hline Albumin & $0.710(0.636 \sim 0.777)$ & 0.072 & 0.003 & 0.232 & \\
\hline CURB-65 & $0.655(0.578 \sim 0.725)$ & 0.086 & 0.073 & 0.067 & 0.645 \\
\hline PSI class & $0.727(0.654 \sim 0.792)$ & 0.057 & $<0.001$ & 0.343 & 0.870 \\
\hline
\end{tabular}

Notes: *Compared with APUA model, ${ }^{\#}$ Compared with Albumin alone.

Abbreviations: AUC, area under curve; $\mathrm{Cl}$, confidence interval; SE, standard error; PSI, pneumonia severity index.

CAP patients on admission, but most patients recovered during follow-up visits. ${ }^{28}$ The decline of serum albumin during early phase after admission was closely correlated with inflammatory proteins. ${ }^{29}$ Therefore, the level of serum albumin reflected the degree of inflammatory response. The lower the level of serum albumin, the more severe was the inflammatory response. Second, serum albumin was associated with the severity of infection. Hypoalbuminemia on admission was an independent risk factor for the development of bacteremia, parapneumonic effusion or empyema in patients with CAP. ${ }^{30,31}$ Third, acute cardiac events were significantly associated with in-hospital mortality in CAP patients.
Hypoalbuminemia was a predictor of acute cardiac events. $^{32,33}$

Some studies have proven that hypoalbuminemia significantly improved the performance of CURB-65 and PSI class for predicting mortality in patients with CAP. ${ }^{17,26,34,35}$ However, CURB-65 and PSI class, particularly PSI class, are complicated scoring systems. Serum albumin makes the systems more complex. In this study, we developed a tool based on serum albumin. After combining with age, pulse and urea, the prognostic performance of serum albumin was increased. The AUCs increased from about 0.7 to about 0.8 .
A

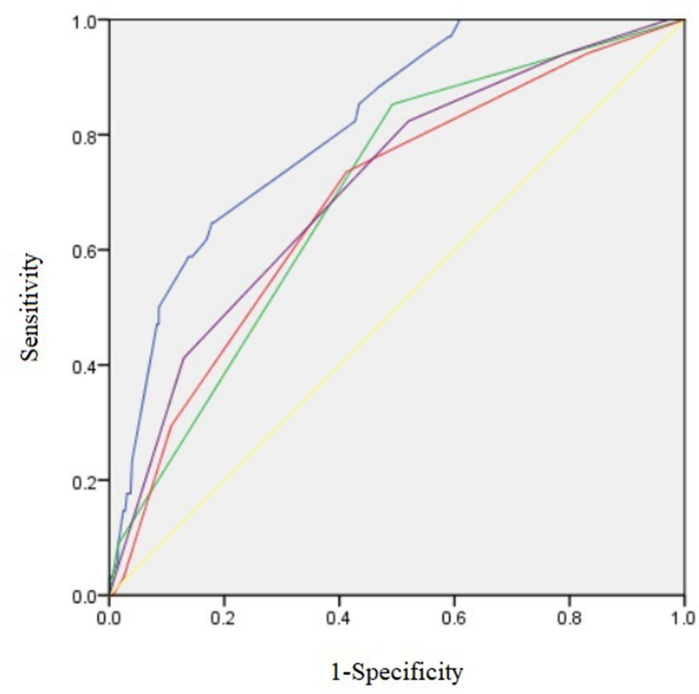

B

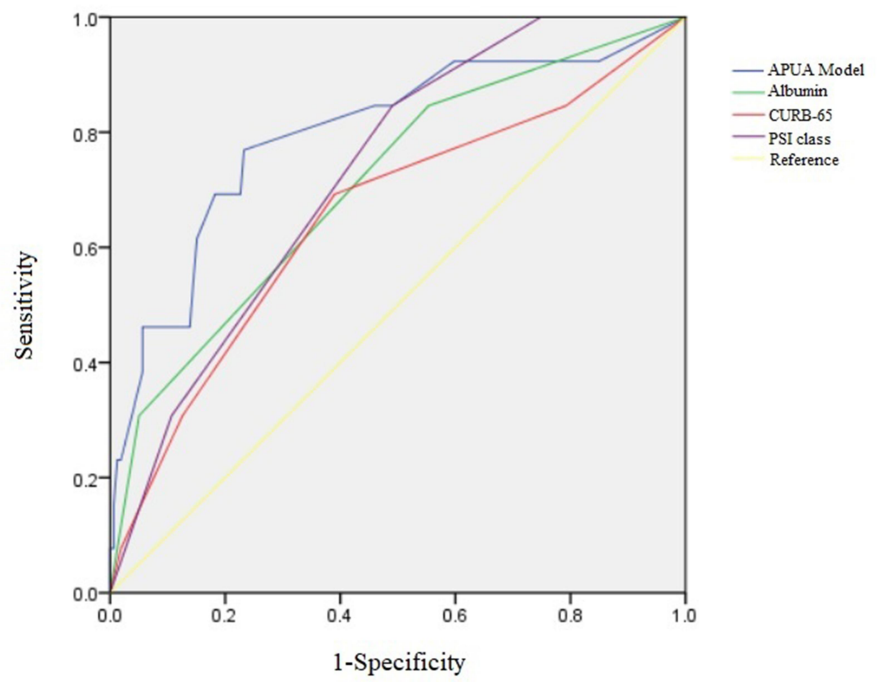

Figure 2 The receiver operator characteristic curve of the APUA model, serum albumin alone, CURB-65 and PSI class for evaluating the risk of in-hospital mortality in community-acquired pneumonia patients with type 2 diabetes. (A) Training set; (B) Validation set. 
Table 5 Comparison of Serum Albumin Alone, CURB-65 and PSI Class with The Accuracy of APUA Model for Evaluating the Risk of in-Hospital Mortality in Community-Acquired Pneumonia Patients with Type 2 Diabetes by NRI and IDI

\begin{tabular}{|l|l|l|l|l|}
\hline Variables & NRI (95\% CI) & $P$ & IDI (95\% CI) & $P$ \\
\hline Training set (N=359) & & & & \\
$\quad$ Albumin & $0.861(0.533 \sim 1.189)$ & $<0.001$ & $0.080(0.032 \sim 0.127)$ & $0.087(0.040 \sim 0.134)$ \\
CURB-65 & $0.766(0.462 \sim 1.070)$ & $<0.001$ & $0.076(0.023 \sim 0.128)$ & 0.001 \\
PSI class & $0.815(0.493 \sim 1.137)$ & $<0.001$ & 0.005 \\
\hline Validation set (N=I72) & & & $0.067(-0.033 \sim 0.167)$ \\
Albumin & $0.599(0.041 \sim 1.157)$ & 0.035 & $0.109(0.027 \sim 0.191)$ & 0.188 \\
CURB-65 & $0.693(0.170 \sim 1.216)$ & 0.009 & $0.086(0.005 \sim 0.168)$ \\
PSI class & $0.643(0.119 \sim 1.166)$ & 0.016 & 0.010 \\
\hline
\end{tabular}

Abbreviations: NRI, net reclassification improvement; IDI, integrated discrimination improvement; Cl, confidence interval; PSI, Pneumonia Severity Index.

This study had some limitations. First, the level of predict mortality in patients with CAP without diabetes, glucose was similar between dead patients and surviving but not with diabetes. ${ }^{36}$ Glycemic gap was associated patients with T2DM. Glucose levels on admission can with mortality in diabetic CAP patients. ${ }^{13}$ Macro and

\section{A}
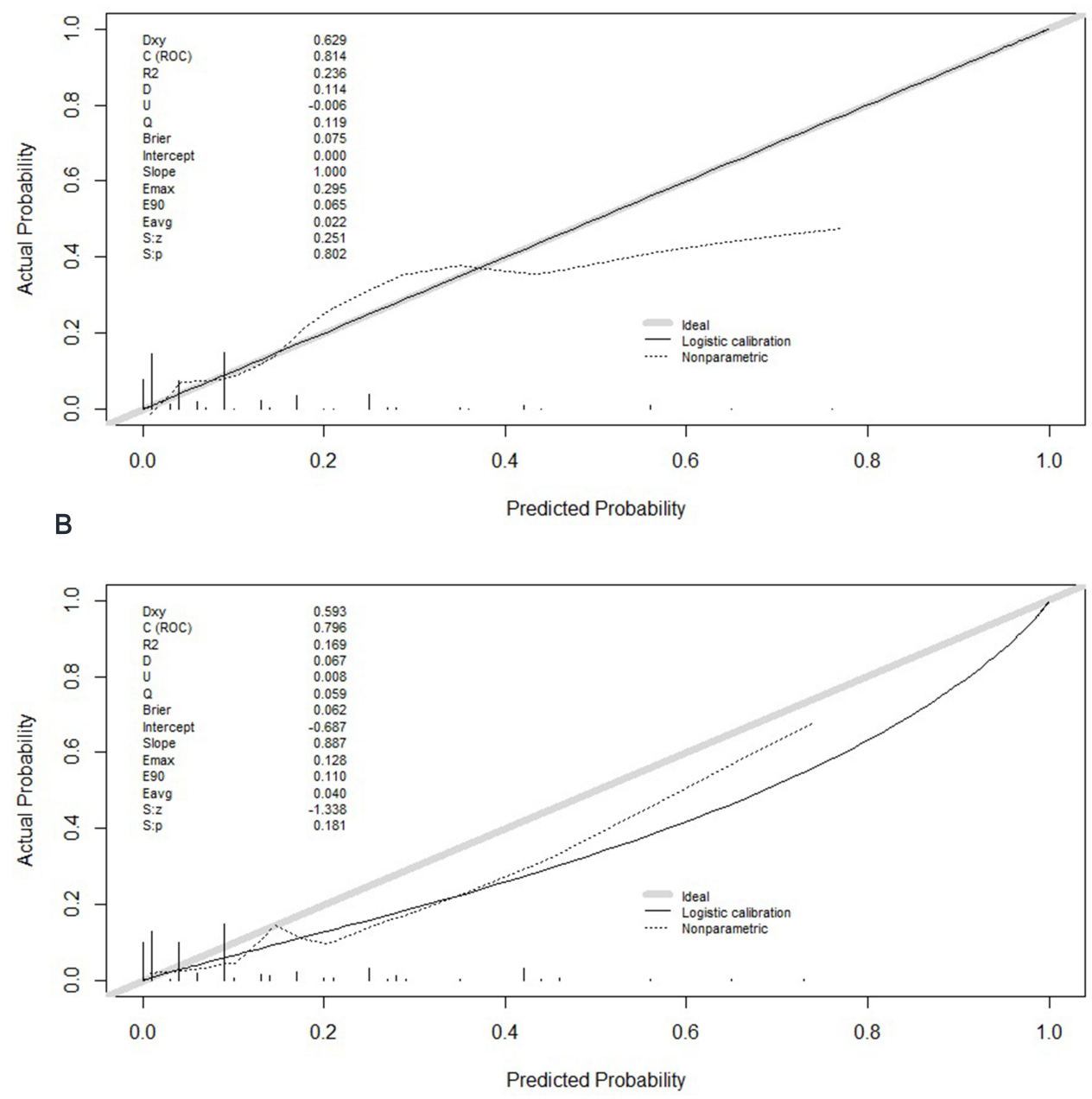

Figure 3 Calibration curves of the APUA model for predicting in-hospital mortality in community-acquired pneumonia patients with type 2 diabetes. (A) Training set; (B) Validation set. 
A

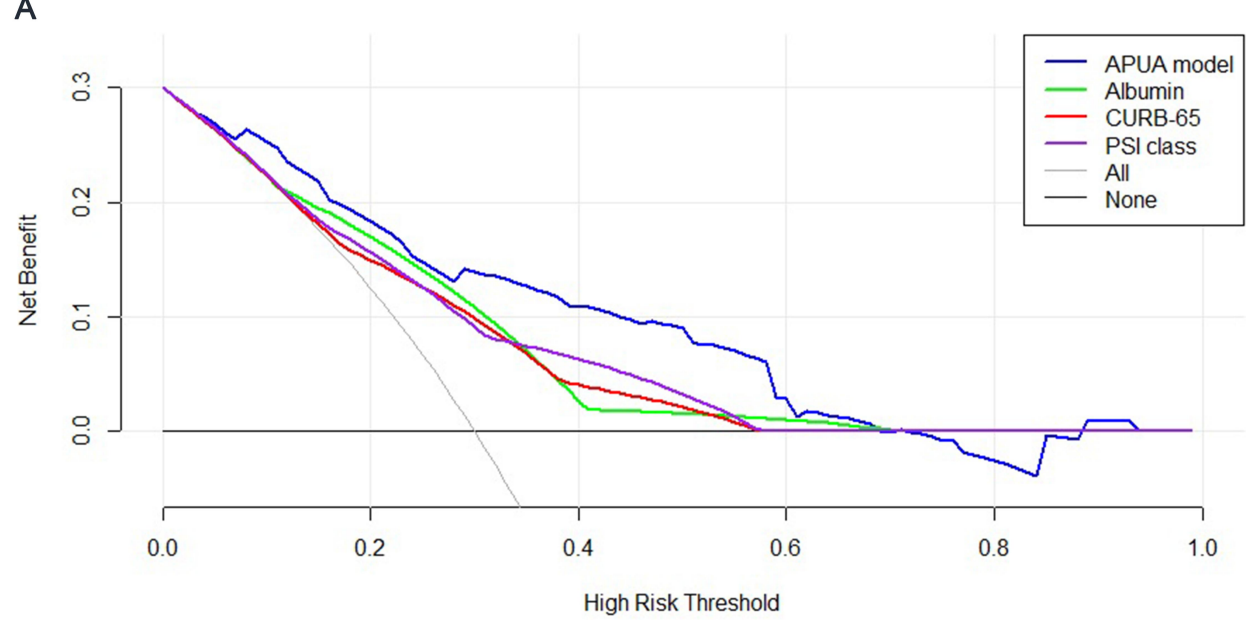

B

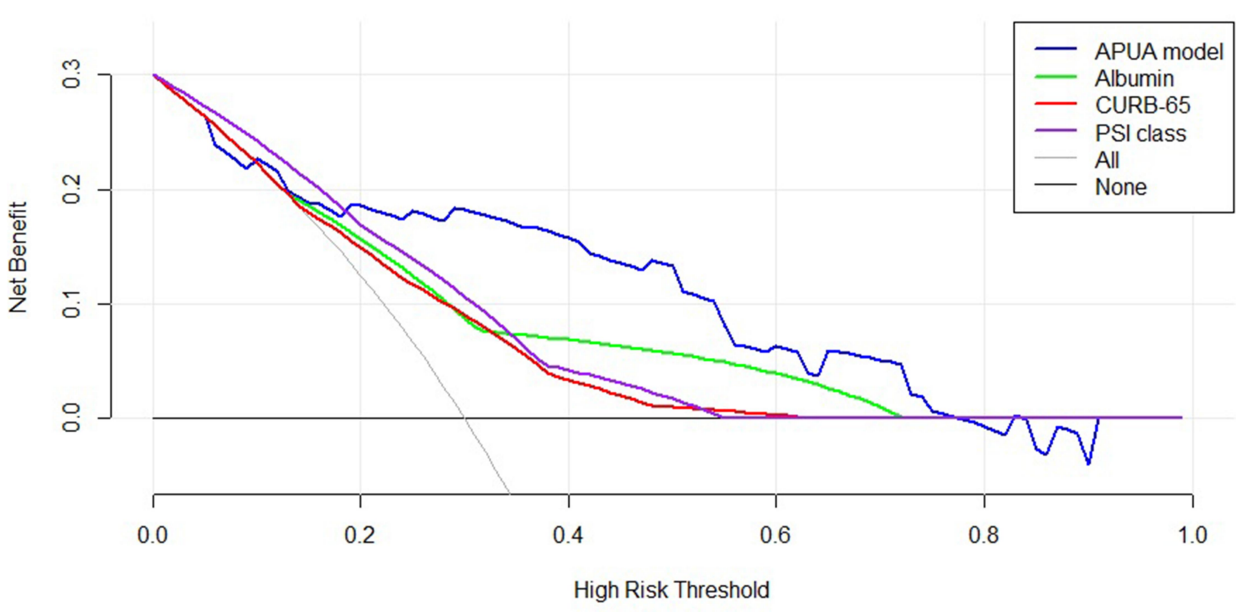

Figure 4 Decision curve analysis of the APUA model for predicting in-hospital mortality in community-acquired pneumonia patients with type 2 diabetes. (A) Training set; (B) Validation set.

microvascular complications also increased infectionrelated mortality in patients with T2DM. ${ }^{37}$ Glycemic gap, micro and macrovascular complications cannot be quickly identified after admission or tested in primary hospital. Therefore, these potential risk factors were not included in this study. However, the validation of the

Table 6 The Sensitivities, Specificities and Youden's Index of APUA Model in Community-Acquired Pneumonia Patients with Type 2 Diabetes

\begin{tabular}{|c|c|c|c|c|c|c|c|c|c|}
\hline \multirow{2}{*}{$\begin{array}{l}\text { Predicted } \\
\text { Risk }\end{array}$} & \multicolumn{3}{|c|}{ Training Set $(N=359)$} & \multicolumn{3}{|c|}{ Validation Set $(\mathrm{N}=\mid 72)$} & \multicolumn{3}{|c|}{ All $(N=53 I)$} \\
\hline & $\begin{array}{l}\text { Sen } \\
(\%)\end{array}$ & $\begin{array}{l}\text { Spe } \\
(\%)\end{array}$ & $\begin{array}{l}\text { Youden's } \\
\text { Index }\end{array}$ & $\begin{array}{l}\text { Sen } \\
(\%)\end{array}$ & $\begin{array}{l}\text { Spe } \\
(\%)\end{array}$ & $\begin{array}{l}\text { Youden's } \\
\text { Index }\end{array}$ & $\begin{array}{l}\text { Sen } \\
(\%)\end{array}$ & $\begin{array}{l}\text { Spe } \\
(\%)\end{array}$ & $\begin{array}{l}\text { Youden's } \\
\text { Index }\end{array}$ \\
\hline $5 \%$ & 88.2 & 53.2 & 0.415 & 84.6 & 50.9 & 0.356 & 87.2 & 52.5 & 0.397 \\
\hline $10 \%$ & 64.7 & 81.8 & 0.466 & 76.9 & 76.7 & 0.537 & 68.1 & 80.2 & 0.483 \\
\hline $20 \%$ & 50.0 & 91.4 & 0.414 & 61.5 & 84.9 & 0.464 & 53.2 & 89.3 & 0.424 \\
\hline $30 \%$ & 17.6 & 96.9 & 0.146 & 46.2 & 94.3 & 0.405 & 25.5 & 96.1 & 0.216 \\
\hline $40 \%$ & 14.7 & 97.5 & 0.122 & 38.5 & 94.3 & 0.328 & 21.3 & 96.5 & 0.178 \\
\hline $50 \%$ & 5.9 & 98.5 & 0.043 & 15.4 & 99.4 & 0.148 & 8.5 & 98.8 & 0.073 \\
\hline
\end{tabular}

Abbreviations: Sen, sensitivity; Spe, specificity. 
Table 7 The Actual Mortality in Patients with Different Predicted Risk of Mortality by APUA Model

\begin{tabular}{|c|c|c|c|c|c|c|}
\hline \multirow[t]{2}{*}{ Predicted Risk of Mortality } & \multirow[t]{2}{*}{$\mathbf{N}$} & \multirow[t]{2}{*}{ Actual Mortality (\%) } & \multicolumn{2}{|l|}{ Model I } & \multicolumn{2}{|l|}{ Model 2} \\
\hline & & & OR $(95 \% \mathrm{Cl})$ & $P$ & OR $(95 \% \mathrm{CI})$ & $P$ \\
\hline $0 \sim 4.9 \%$ & 260 & 2.3 & I & & I & \\
\hline $5 \sim 9.9 \%$ & 143 & 6.3 & $2.843(0.99 \mid \sim 8.157)$ & 0.052 & $2.293(0.764 \sim 6.879)$ & 0.139 \\
\hline $10 \sim 19.9 \%$ & 51 & 13.7 & $6.735(2.162 \sim 20.983)$ & 0.001 & $5.028(\mid .469 \sim 17.206)$ & 0.010 \\
\hline $20 \sim 29.9 \%$ & 46 & 28.3 & 16.677(5.935 46.857) & $<0.001$ & I I. $195(3.325 \sim 37.699)$ & $<0.001$ \\
\hline$\geq 30 \%$ & 31 & 38.7 & $26.737(9.033 \sim 79.142)$ & $<0.001$ & I5.039(3.594 62.928) & $<0.001$ \\
\hline
\end{tabular}

Notes: Model I: univariate logistic regression analysis. Model 2: multiple logistic regression analysis, adjusted for sex, age and PSI score.

Abbreviations: $\mathrm{OR}$, odds ratio; $\mathrm{Cl}$, confidence interval; $\mathrm{PSI}$, pneumonia severity index.

APUA model based on four risk factors demonstrated a good performance. Second, we performed an internal validation in this study, but the validation population was small. So the APUA model should be validated in a larger population.

In summary, the APUA model is a simple and accurate tool for predicting in-hospital mortality of CAP, adapted for patients with T2DM. The predictive performance of the APUA model was better than the CURB-65 and PSI class.

\section{Consent Statement}

This was a retrospective study. Data were extracted from the Hospital Information System. We covered patient data confidentiality. Personal information of the patients, such as name and telephone number, were not extracted. So Informed consent was waived by the ethics committee of the First Hospital of Qinhuangdao, and this study complied with the Declaration of Helsinki.

\section{Disclosure}

The authors have no relevant funding and conflicts of interest to disclose.

\section{References}

1. Jain S, Self WH, Wunderink RG, et al. Community-acquired pneumonia requiring hospitalization among U.S. adults. $N$ Engl $J$ Med. 2015;373:415-427. doi:10.1056/NEJMoa1500245

2. Partouche H, Lepoutre A, Vaure CBD, Poisson T, Toubiana L, Gilberg S. Incidence of all-cause adult community-acquired pneumonia in primary care settings in France. Med Mal Infect. 2018;48:389-395. doi:10.1016/j.medmal.2018.02.012

3. Lopardo GD, Fridman D, Raimondo E, et al. Incidence rate of community-acquired pneumonia in adults: a population-based prospective active surveillance study in three cities in South America. BMJ Open. 2018;8:e019439.

4. Takaki $M$, Nakama $T$, Ishida $M$, et al. High incidence of community-acquired pneumonia among rapidly aging population in Japan: a prospective hospital-based surveillance. Jpn J Infect Dis. 2014;67:269-275. doi:10.7883/yoken.67.269
5. Heo JY, Seo YB, Choi WS, et al. Incidence and case fatality rates of community-acquired pneumonia and pneumococcal diseases among Korean adults: catchment population-based analysis. PLoS One. 2018;13:e0194598. doi:10.1371/journal.pone.0194598

6. International Diabetes Federation. IDF diabetes atlas, 9th edn. Brussels, Belgium; 2019. Available from: http://www.diabetesatlas. org. Accessed September 16, 2020.

7. Torres A, Blasi F, Dartois N, Akova M. Which individuals are at increased risk of pneumococcal disease and why? Impact of COPD, asthma, smoking, diabetes, and/or chronic heart disease on community-acquired pneumonia and invasive pneumococcal disease. Thorax. 2015;70:984-989. doi:10.1136/thoraxjnl-2015-206780

8. Cao B, Huang Y, She DY, et al. Diagnosis and treatment of community-acquired pneumonia in adults: 2016 clinical practice guidelines by the Chinese Thoracic Society, Chinese Medical Association. Clin Respir J. 2018;12:1320-1360.

9. Metlay JP, Waterer GW, Long AC, et al. Diagnosis and treatment of adults with community-acquired pneumonia. An official clinical practice guideline of the American Thoracic Society and Infectious Diseases Society of America. Am J Respir Crit Care Med. 2019;200:e45-e67. doi:10.1164/rccm.201908-1581ST

10. Lim WS, Baudouin SV, George RC, et al. BTS guidelines for the management of community acquired pneumonia in adults: update 2009. Thorax. 2009;64(Suppl 3):iii1-55. doi:10.1136/thx.2009.121434

11. Boyles TH, Brink A, Calligaro GL, et al.; South African Thoracic S and Federation of Infectious Diseases Societies of Southern A. South African guideline for the management of community-acquired pneumonia in adults. $J$ Thorac Dis. 2017;9:1469-1502. doi:10.21037/ jtd.2017.05.31

12. Chalmers JD, Singanayagam A, Akram AR, et al. Severity assessment tools for predicting mortality in hospitalised patients with community-acquired pneumonia. Systematic review and meta-analysis. Thorax. 2010;65:878-883. doi:10.1136/thx.2009.133280

13. Chen PC, Liao WI, Wang YC, et al. An elevated glycemic gap is associated with adverse outcomes in diabetic patients with community-acquired pneumonia. Medicine (Baltimore). 2015;94: e1456. doi:10.1097/MD.0000000000001456

14. Irfan M, Hussain SF, Mapara K, et al. Community acquired pneumonia: risk factors associated with mortality in a tertiary care hospitalized patients. J Pak Med Assoc. 2009;59:448-452.

15. Naffaa ME, Mustafa M, Azzam M, et al. Serum inorganic phosphorus levels predict 30-day mortality in patients with community acquired pneumonia. BMC Infect Dis. 2015;15:332. doi:10.1186/ s12879-015-1094-6

16. Holter JC, Ueland T, Jenum PA, et al. Risk factors for long-term mortality after hospitalization for community-acquired pneumonia: a 5-year prospective follow-up study. PLoS One. 2016;11:e0148741. doi:10.1371/journal.pone. 0148741

17. Viasus D, Garcia-Vidal C, Simonetti A, et al. Prognostic value of serum albumin levels in hospitalized adults with community-acquired pneumonia. J Infect. 2013;66:415-423. doi:10.1016/j.jinf.2012.12.007 
18. Han X, Zhou F, Li H, et al. Effects of age, comorbidity and adherence to current antimicrobial guidelines on mortality in hospitalized elderly patients with community-acquired pneumonia. BMC Infect Dis. 2018;18:192. doi:10.1186/s12879-018-3098-5

19. Sanz-Paris A, Martin-Palmero A, Gomez-Candela C, et al. GLIM criteria at hospital admission predict 8-year all-cause mortality in elderly patients with type 2 diabetes mellitus: results from VIDA study. JPEN J Parenter Enteral Nutr. 2020. doi:10.1002/jpen.1781

20. Jeyaraman K, Berhane T, Hamilton M, Chandra AP, Falhammar H. Mortality in patients with diabetic foot ulcer: a retrospective study of 513 cases from a single Centre in the Northern Territory of Australia. BMC Endocr Disord. 2019;19:1. doi:10.1186/s12902-018-0327-2

21. D'Alessandro C, Barsotti M, Cianchi C, et al. Nutritional aspects in diabetic CKD patients on tertiary care. Medicina (Kaunas). 2019;55.

22. Huang $\mathrm{CH}$, Chiu $\mathrm{CH}$, Chen IW, et al. Antimicrobial resistance and outcomes of community-onset bacterial bloodstream infections in patients with type 2 diabetes. $J$ Glob Antimicrob Resist. 2018;15:271-276. doi:10.1016/j.jgar.2018.08.008

23. Huang CH, Tsai JS, Chen IW, Hsu BR, Huang MJ, Huang YY. Risk factors for in-hospital mortality in patients with type 2 diabetes complicated by community-acquired Klebsiella pneumoniae bacteremia. J Formos Med Assoc. 2015;114:916-922. doi:10.1016/j. jfma.2015.07.011

24. Lim WS, van der Eerden MM, Laing R, et al. Defining community acquired pneumonia severity on presentation to hospital: an international derivation and validation study. Thorax. 2003;58:377-382. doi:10.1136/thorax.58.5.377

25. Fine MJ, Auble TE, Yealy DM, et al. A prediction rule to identify low-risk patients with community-acquired pneumonia. $N$ Engl J Med. 1997;336:243-250. doi:10.1056/NEJM199701233360402

26. Yeon Lee S, Cha SI, Seo H, et al. Multimarker prognostication for hospitalized patients with community-acquired pneumonia. Intern Med. 2016;55:887-893. doi:10.2169/internalmedicine.55.5764

27. Miyazaki H, Nagata N, Akagi T, et al. Comprehensive analysis of prognostic factors in hospitalized patients with pneumonia occurring outside hospital: serum albumin is not less important than pneumonia severity assessment scale. J Infect Chemother. 2018;24:602-609. doi:10.1016/j.jiac.2018.03.006
28. Hedlund J. Community-acquired pneumonia requiring hospitalisation. Factors of importance for the short-and long term prognosis. Scand J Infect Dis Suppl. 1995;97:1-60.

29. Harimurti K, Setiati S. C-reactive protein levels and decrease of albumin levels in hospitalized elderly patients with community-acquired pneumonia. Acta Med Indones. 2007;39:13-18.

30. Washio Y, Ito A, Kumagai S, Ishida T, Yamazaki A. A model for predicting bacteremia in patients with community-acquired pneumococcal pneumonia: a retrospective observational study. BMC Pulm Med. 2018;18:24. doi:10.1186/s12890-018-0572-1

31. Chalmers JD, Singanayagam A, Murray MP, Scally C, Fawzi A, Hill AT. Risk factors for complicated parapneumonic effusion and empyema on presentation to hospital with community-acquired pneumonia. Thorax. 2009;64:592-597. doi:10.1136/thx.2008.105080

32. Cilli A, Cakin O, Aksoy E, et al. Acute cardiac events in severe community-acquired pneumonia: a multicenter study. Clin Respir J. 2018;12:2212-2219. doi:10.1111/crj.12791

33. Viasus D, Garcia-Vidal C, Manresa F, Dorca J, Gudiol F, Carratala J. Risk stratification and prognosis of acute cardiac events in hospitalized adults with community-acquired pneumonia. J Infect. 2013; 66:27-33. doi:10.1016/j.jinf.2012.09.003

34. Lee JH, Kim J, Kim K, et al. Albumin and C-reactive protein have prognostic significance in patients with community-acquired pneumonia. J Crit Care. 2011;26:287-294. doi:10.1016/j.jcrc.2010. 10.007

35. Liu JL, Xu F, Zhou H, et al. Expanded CURB-65: a new score system predicts severity of community-acquired pneumonia with superior efficiency. Sci Rep. 2016;6:22911. doi:10.1038/srep22911

36. Lepper PM, Ott S, Nuesch E, et al.; German Community Acquired Pneumonia Competence N. Serum glucose levels for predicting death in patients admitted to hospital for community acquired pneumonia: prospective cohort study. BMJ. 2012;344:e3397. doi:10.1136/bmj. e3397

37. Cardoso CR, Salles GF. Macro and microvascular complications are determinants of increased infection-related mortality in Brazilian type 2 diabetes mellitus patients. Diabetes Res Clin Pract. 2007;75:51-58. doi:10.1016/j.diabres.2006.04.008

\section{Publish your work in this journal}

Diabetes, Metabolic Syndrome and Obesity: Targets and Therapy is an international, peer-reviewed open-access journal committed to the rapid publication of the latest laboratory and clinical findings in the fields of diabetes, metabolic syndrome and obesity research. Original research, review, case reports, hypothesis formation, expert opinion and commentaries are all considered for publication. The manuscript management system is completely online and includes a very quick and fair peer-review system, which is all easy to use. Visit http://www.dovepress.com/testimonials.php to read real quotes from published authors. 